\author{
Military Technical College \\ Kobry El-Kobbah, \\ Cairo, Egypt.
}

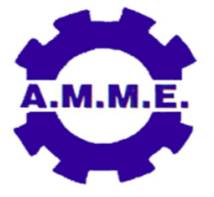

\title{
3-D NUMERICAL STUDY OF THE EFFECT OF IMPELLER BLADES SLOT ON THE CENTRIFUGAL PUMP PERFORMANCE USING CFD
}

\author{
A. F. Ayad ${ }^{1}$, H. M. Abdalla ${ }^{1}$ and A. S. Abo El-Azm ${ }^{1}$
}

\begin{abstract}
The effect of impeller backward blades with slot on the centrifugal pump performance has been investigated numerically. Impeller blades have been modified with different geometrical parameters of slot such as: slot radial position $\left(R_{S}\right)$, slot height $\left(h_{s}\right)$ and slot inclination angle $\left(\theta_{s}\right)$. 3-D numerical simulation has been carried out using commercial software, ANSYS® CFX, to study the effect on the pump performance at different flow rates. The numerical simulation has been compared with previously published experimental results to verify the numerical solution. In addition, the results have been compared with the impeller without slots for the same operating conditions. It has been shown that the slot parameters have a significant effect on the centrifugal impeller performance.
\end{abstract}

\section{KEYWORDS}

Computational Fluid Dynamics (CFD), Blade slot, Centrifugal Pump Performance.

\footnotetext{
${ }^{1}$ Egyptian armed forces
} 


\section{INTRODUCTION}

Centrifugal pumps are probably among the most often used machinery in industrial facilities as well as in common practice. After being invented, they passed long evolutionary way until they became accessible for various applications. A few centuries ago, Euler described their physical principle through a well-known equation named after him "Euler's equation for turbomachinery".

Since then, many studies have been conducted to improve the centrifugal pump performance. These studies used a lot of methods and ideas seeking a better centrifugal pump performance through attempts to increase the pump total efficiency and slip factor.

One of these methods that took a lot of interest was to improve the pump performance by impeller trimming [1-4]. These studies found that as the diameter is reduced, the head and power curves decrease continuously. The efficiency, however, will increase at first and then drop for a certain value of diameter. The main reason for this might be attributed to the growth of the gap between the impeller and stator as the impeller diameter is reduced.

Another attempt to improve the centrifugal pump performance lies in adding splitter blades between the main blades [5-7]. Unfortunately, such solution was found to render negative and positive effects on the pump behavior. It increases the head as compared to the original impeller. This was explained by the fact that increasing the impeller slip factor in effect of the splitter would help better conduct energy to the flow. However, a drop in total efficiency has been noticed in some cases due to the increase of the hydraulic friction between the pumping fluid and the splitter blades.

The pump geometrical parameters remain the greatest interest of all researchers looking for improving the centrifugal pump performance. Some authors made optimization on the blade exit angle and they found that with increasing the blade exit angle the head increases but the efficiency decreases [8-12]. Some other authors conducted optimization on the number of blades [13-15]. They concluded that when increasing the number of blades, both head and efficiency increase until a certain number of blades at which the efficiency decreases. Other authors considered the blade outlet width in their optimization research [16, 17]. It was found that at the design flow rate, the head increases gradually with the progressive increments of blade outlet width. In addition, the high efficiency area in the large flow rate region gets bigger and the area in low flow rate region changes a little with the increase of blade outlet width.

Some authors tried to improve the pump performance by making a slot in the impeller blade. The first one who start adopting this technique was E.A. Ahmed [18, 19]. Then, M. Saffaa and his group [20-22] developed this work using their own 2-D numerical code to solve a laminar flow inside the pump impeller. In an attempt to examine the effect on the pump performance, Hongxun [23] used a similar technique and made a comparison between the draughting technique and the splitter blades.

In the present work, a parametric study is attempted, based on the blade slot technique to investigate the effect of three slot geometrical parameters, namely slot 
radial position $\left(R_{s}\right)$, slot height $\left(h_{s}\right)$ and slot inclination angle $\left(\theta_{s}\right)$ on the impeller performance. The study implements a 3-D numerical simulation of turbulent flow inside the centrifugal impeller.

\section{COMPUTATIONAL MODEL}

\section{Geometrical Models}

The centrifugal pump impeller used by [20, 24], shown in Figure (1), is chosen as a geometrical model to apply numerical computation. The main metrics of pump design and performance are listed in Table (1).

Table (1) Pump dimensions and operating conditions.

\begin{tabular}{|l|c|l|c|}
\hline Operating Flow Rate $(\mathrm{Q})$ & 3.25 liter/s & Blades Number $(\mathrm{Z})$ & 6 \\
\hline Head $(\mathrm{H})$ & $6.5 \mathrm{~m}$ & Blade discharge angle $\left(\beta_{2}\right)$ & $20^{\circ}$ \\
\hline Rotational Speed $(\mathrm{n})$ & $1500 \mathrm{rpm}$ & Blade inlet angle $\left(\beta_{1}\right)$ & $35^{\circ}$ \\
\hline $\begin{array}{l}\text { Impeller Inlet Diameter } \\
\left(\mathrm{D}_{1}\right)\end{array}$ & $50 \mathrm{~mm}$ & Blade Outlet Width $\left(\mathrm{b}_{2}\right)$ & $12 \mathrm{~mm}$ \\
\hline $\begin{array}{l}\text { Impeller Outlet Diameter } \\
\left(\mathrm{D}_{2}\right)\end{array}$ & $130 \mathrm{~mm}$ & Blade inlet Width $\left(\mathrm{b}_{1}\right)$ & $15 \mathrm{~mm}$ \\
\hline
\end{tabular}

The flow patterns and the hydraulic performance of the isolated impeller (without volute) must differ from that of the impeller with volute[25]. This difference is due to impeller-volute interactions. In this work, only an isolated impeller has been considered. This is justified by the need to simplify the present study that is considered as a preliminary investigation.

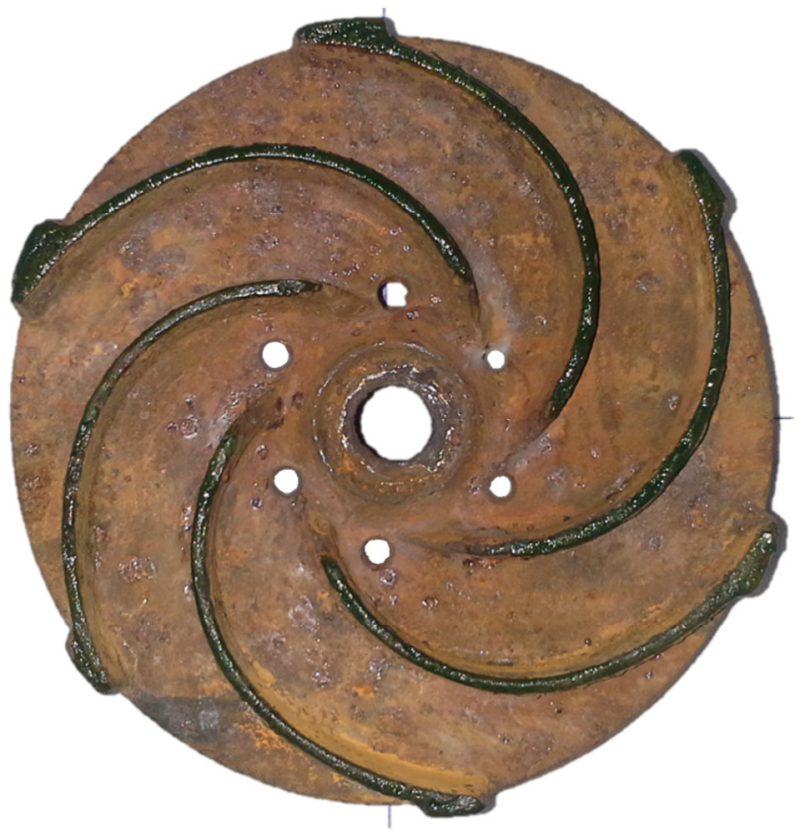

Figure (1). Centrifugal impeller with backward blades. 
Two geometrical models have been generated as shown in Figure (2). Model MI represent the impeller without slot. Model M2 represent the impeller with slot. The slot has three parameters have been varied: the slot radial position $\left(R_{S}\right)$, the slot height $\left(h_{s}\right)$ and the slot inclination angle $\left(\theta_{s}\right)$. Slot inclination angle is measured between slot axis and the local tangent to a circle with radius equal to the slot radial position.

(-ve) Inclination

No Inclination

(+ve) Inclination
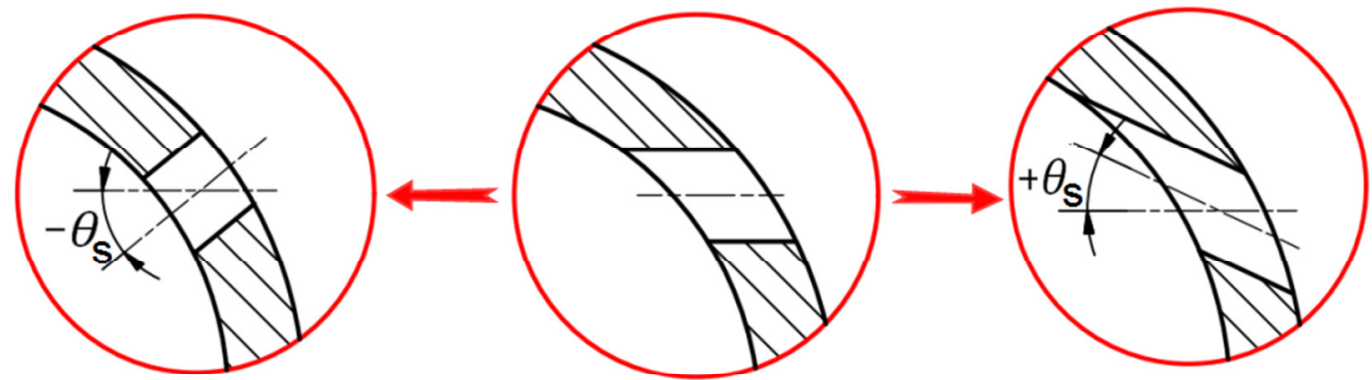

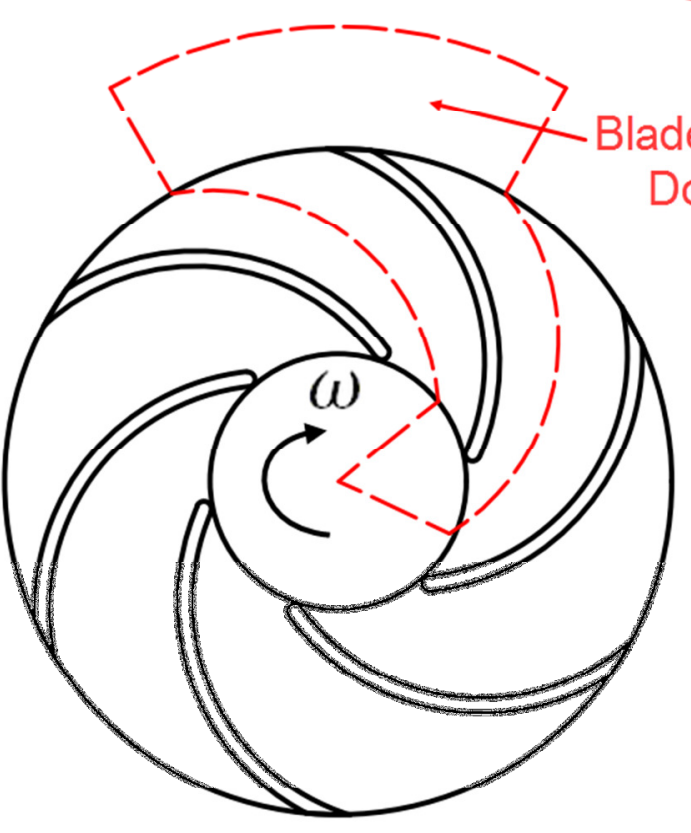

M1

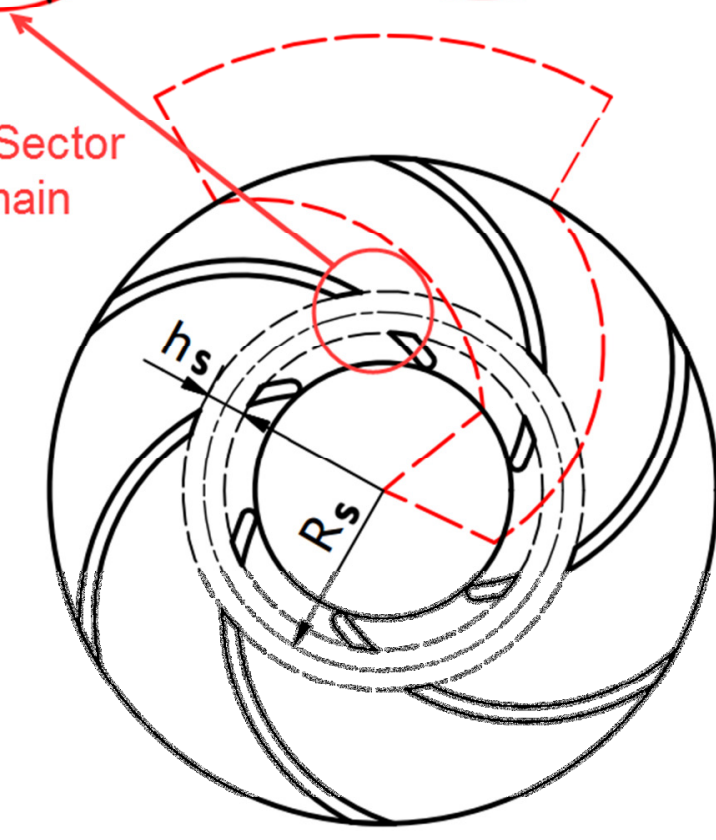

M2

Figure (2) Two geometrical models: M1 impeller blade sector without slot, M2 impeller blade sector with slot.

\section{Governing Equations}

Numerical simulation is carried out using ANSYS® CFX to solve the governing equations. Since the pumped fluid is incompressible and the flow is in a steady state, the continuity equation has the following form[26]:

$$
\frac{\partial u_{i}}{\partial x_{j}}=0
$$

In addition, the equation of conservation of momentum together with the definition of the source term, and the shear stress is expressed as Eq. (2) 


$$
\frac{\partial}{\partial x_{j}}\left(\rho \bar{u}_{i} \bar{u}_{j}\right)=\frac{-\partial \bar{P}}{\partial x_{i}}+\frac{\partial}{\partial x_{j}}\left(\bar{\tau}_{i j}-\rho \overline{\overline{u_{i} u_{j}}}\right)+S_{u_{i}}
$$

where the source term (including the centrifugal and Coriolis force terms) is written as Eq. (3) and the average shear stress is obtained from Eq. (4):

$$
\begin{gathered}
S_{u_{i}}=-\rho[2 \vec{\omega} \times \vec{u}+\vec{\omega} \times(\vec{\omega} \times \vec{r})] \\
\bar{\tau}_{i j}=-\mu\left(\frac{\partial \bar{u}_{i}}{\partial x_{j}}+\frac{\partial \bar{u}_{j}}{\partial x_{i}}\right)
\end{gathered}
$$

\section{Computational Domain}

The computational domain consists of three zones: inlet, impeller and outlet as shown in Figure (3). They are defined by means of the multi-reference frame technique. The impeller is situated in the rotating reference frame, the inlet and outlet zones are in the fixed reference frame, and they are related to each other through the "frozen rotor" interface. The frozen rotor method [26] employs a quasi-steady algorithm, where the rotor and stator are modeled at a fixed (frozen) position relative to each other. Rotational terms are included in the moving frames, while the transient effects are neglected. This provides an efficient method for the calculation of interactions between impellers and outlet zone, and is a practical option for compact machines with small distances between rotor and stator. In this way, the solution provides a snapshot of the flow regime. When the Navier-Stokes equations of motion are solved in a rotating reference frame, the fluid accelerations due to rotation appear as an additional terms in the momentum equations, Eq. (3).

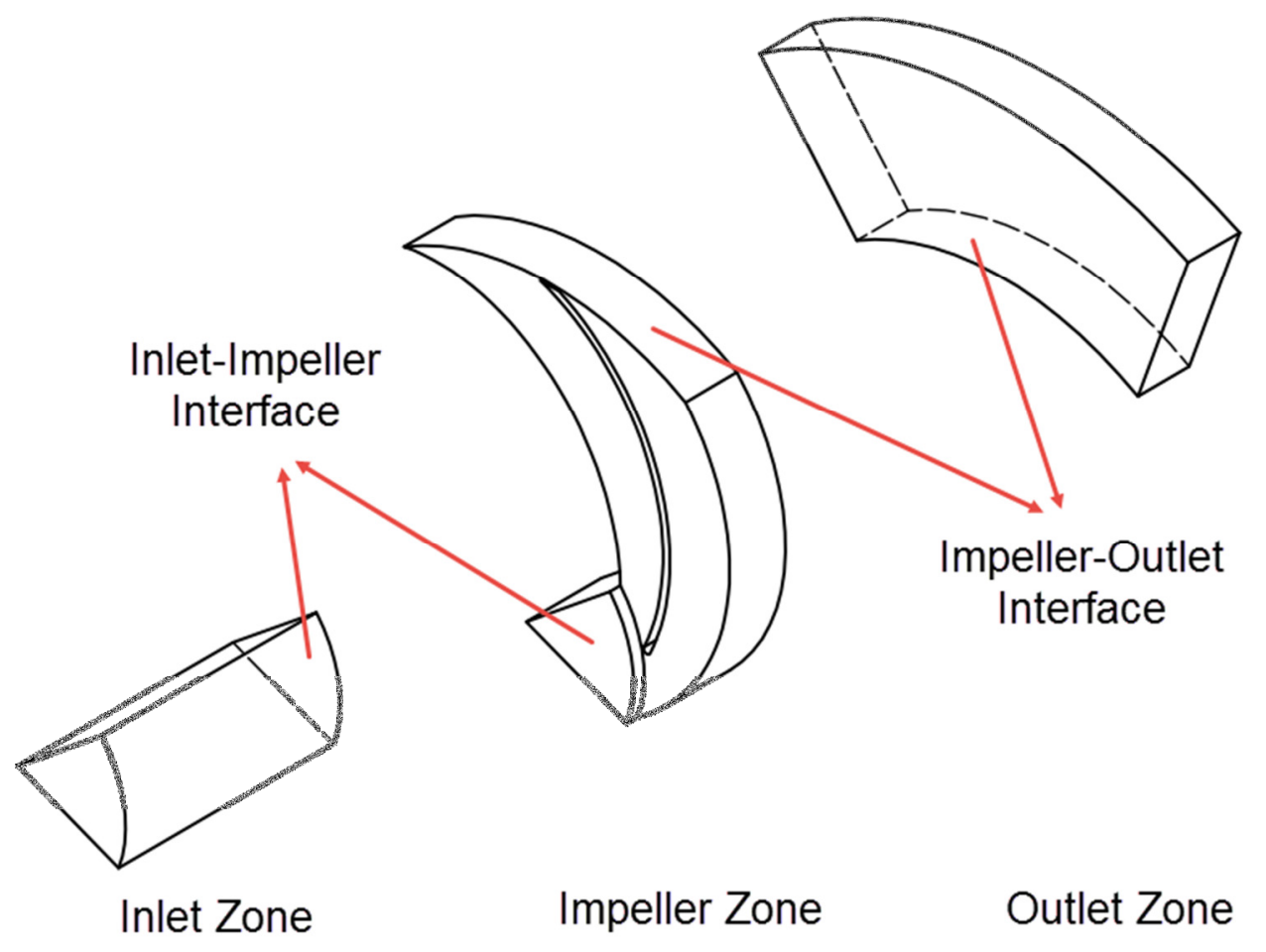

Figure (3) Computational Domain (inlet-impeller-outlet) zones. 


\section{Domain Discretization}

The meshes of three computational domains - the inlet section, the impeller, and the outlet section - are generated separately after performing mesh sensitivity analysis as shown in Figure (4). In this analysis, localized refinements of mesh are employed at regions close to the blade slot, the impeller blade and the blade leading and trailing edges in order to accurately capture the dominant flow field structure. The motive of this localized mesh refinement is to encounter considerable variations of flow field properties such as pressure and velocity at those regions.

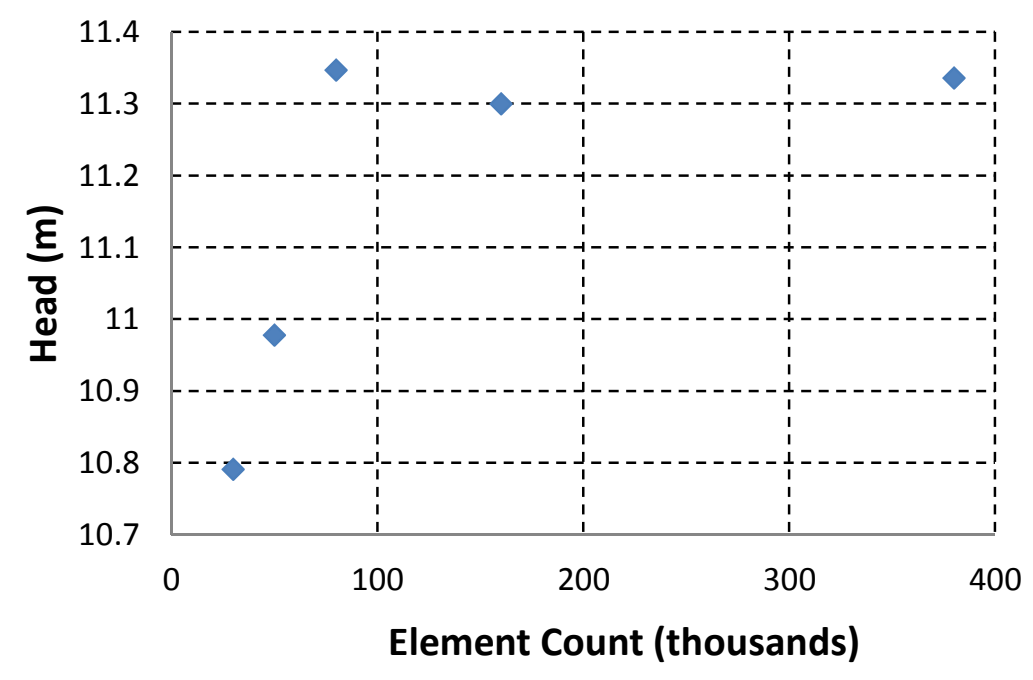

Figure (4). Result of mesh Sensitivity Analysis $(Q=3$ liter/s).

The inlet and outlet section domains include 2550 and 9150 hexahedrons elements, respectively, while impeller and slot domain include 96603 and 11312 tetrahedrons elements, respectively, Figure (5). To cope with the complicated domain topology a combination of structured and unstructured grids is used.

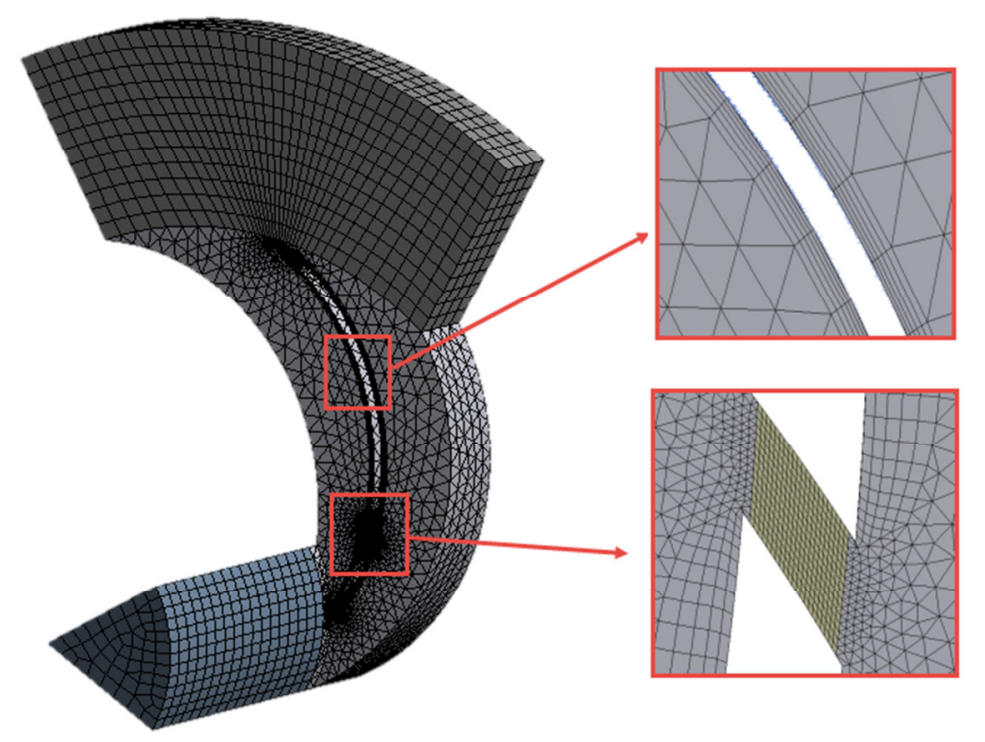

Figure (5) Inlet, impeller and outlet domain mesh. 


\section{Boundary Conditions and Zones Interface}

The boundary conditions are set as mass flow at inlet and the static pressure at outlet. A rotational periodicity is adopted at the other outer boundaries of the domain. A no-slip condition is imposed at the wall boundary defined at the blade. The impeller zone is modeled in the rotating frame, and the outlet and the inlet zones are modeled in the fixed reference frame. Figure (6) illustrate the definition of the boundary conditions.

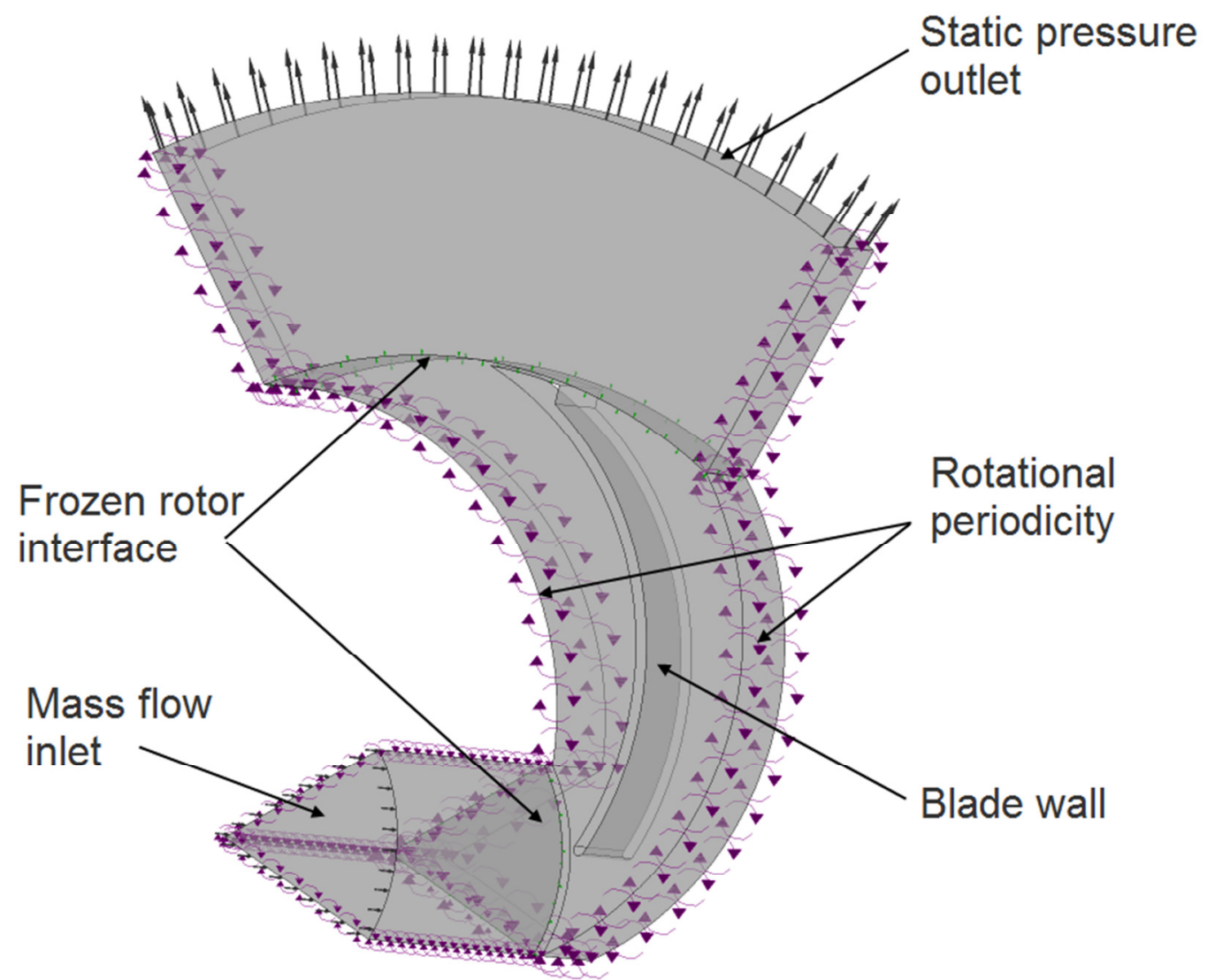

Figure (6). Boundary conditions and zones interface.

\section{Turbulence Model}

With the help of the mixing function value, the shear stress transport (SST) model automatically uses the $k-\omega$ model in the near-wall regions and the $k-\varepsilon$ model in the regions away from the wall. This model modifies the energy production term in the kinetic energy transfer equation [27]. Considering the studies conducted on the two models of $k-\varepsilon$ and $R N G k-\varepsilon$, it is concluded that the near-wall flow can be evaluated with high precision using the $k-\varepsilon$ model and the SST function. The obtained results show better accuracy than those of the $k-\varepsilon$ model alone. Therefore, the SST turbulence model is used for the numerical investigation of flow inside the centrifugal pump.

\section{Convergence Criteria of the Numerical Simulations}

The numerical solution has convergence precision of residuals up to $10^{-6}$. Figure (7) shows the history of convergence. 


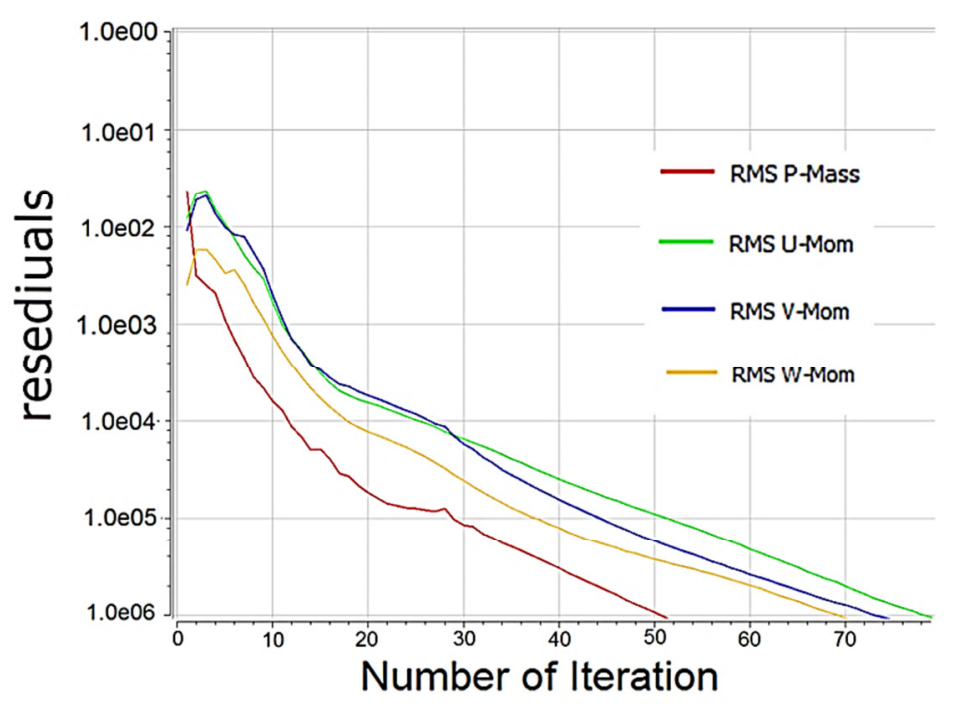

Figure (7) Residual history versus number of iterations.

\section{VALIDATION OF THE NUMERICAL SIMULATION}

The comparison between the experimentally measured impeller performance with and without blade slot in reference [20] is used to validate the present study. The pump with slot has the following parameters: slot radial position $R_{s}=35 \mathrm{~mm}$, slot height $h_{s}=8 \mathrm{~mm}$ and the inclination angle $\theta_{s}=0^{\circ}$ at rotational speed $n=2000 \mathrm{rpm}$. Here, the pump head and hydraulic efficiency are calculated according to reference [28] by using Eq. (5) and Eq.(6), respectively

$$
\begin{gathered}
H=\frac{P_{t_{\text {out }}}-P_{t_{\text {in }}}}{\rho g} \\
\eta_{h_{\text {imp }}}=\frac{\frac{\dot{m}}{\rho}\left(P_{t_{\text {out }}}-P_{t_{\text {in }}}\right)}{T \cdot \omega}
\end{gathered}
$$

Figure (8) and Figure (9) show the variation of the impeller head and hydraulic efficiency with flow rate, respectively, for both impellers with and without slot. Experimental measurement show that the slot with the parameters of reference [20] reduces the impeller head. The slot shows a minor impact on the efficiency however, adding the slot increases the efficiency below the operating point and reduces the efficiency beyond the operating point. These effects of adding slot could be explained by the considerable reduction in the effective blade length and augmentation of flow rate through the slot, which in this case represents about $17 \%$ of the design flow rate.

Despite the apparent discrepancy between experimental and numerical results, the numerical simulations predict the same trend of head and efficiency. They also predict the same effect of slot on pump head at all flow rates and efficiency at high flow rate only. This discrepancy could be attributed to the omission of the volute and leakage effects in the numerical simulation. 


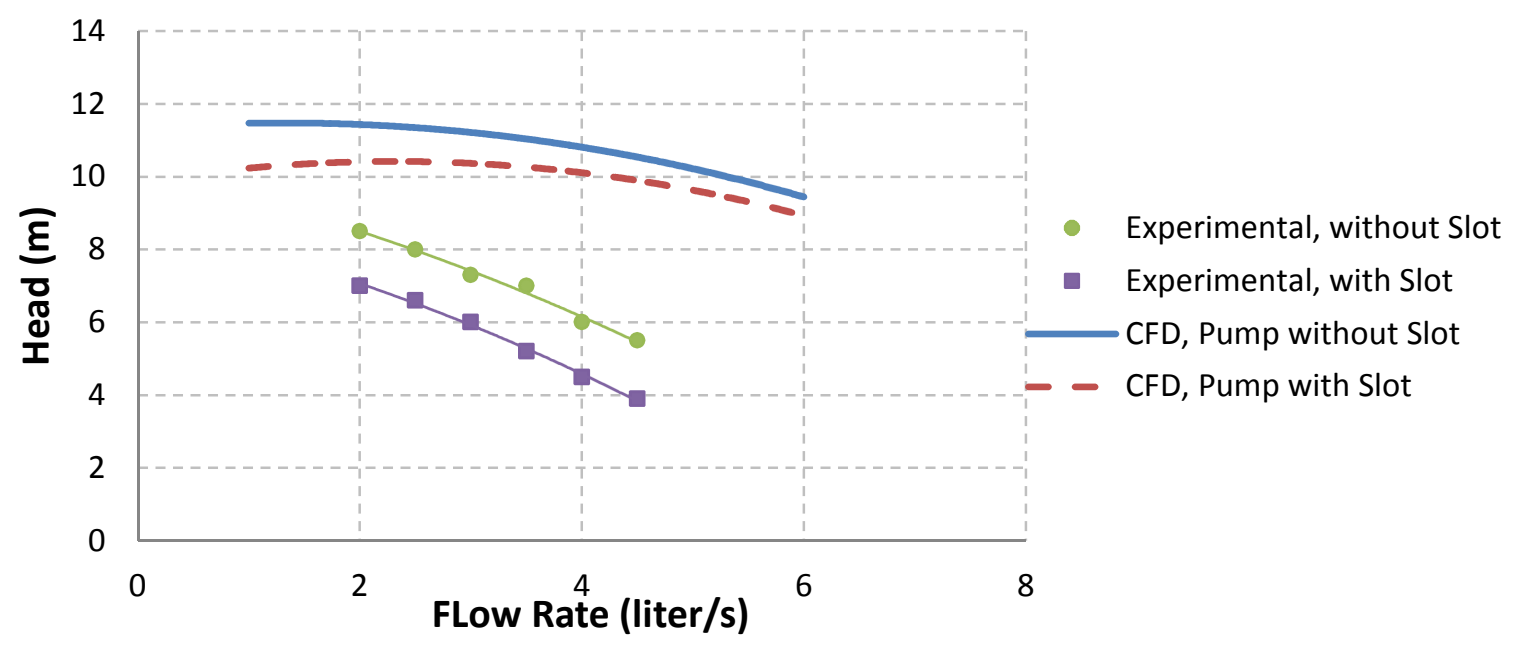

Figure (8). Pump characteristics with and without slot.

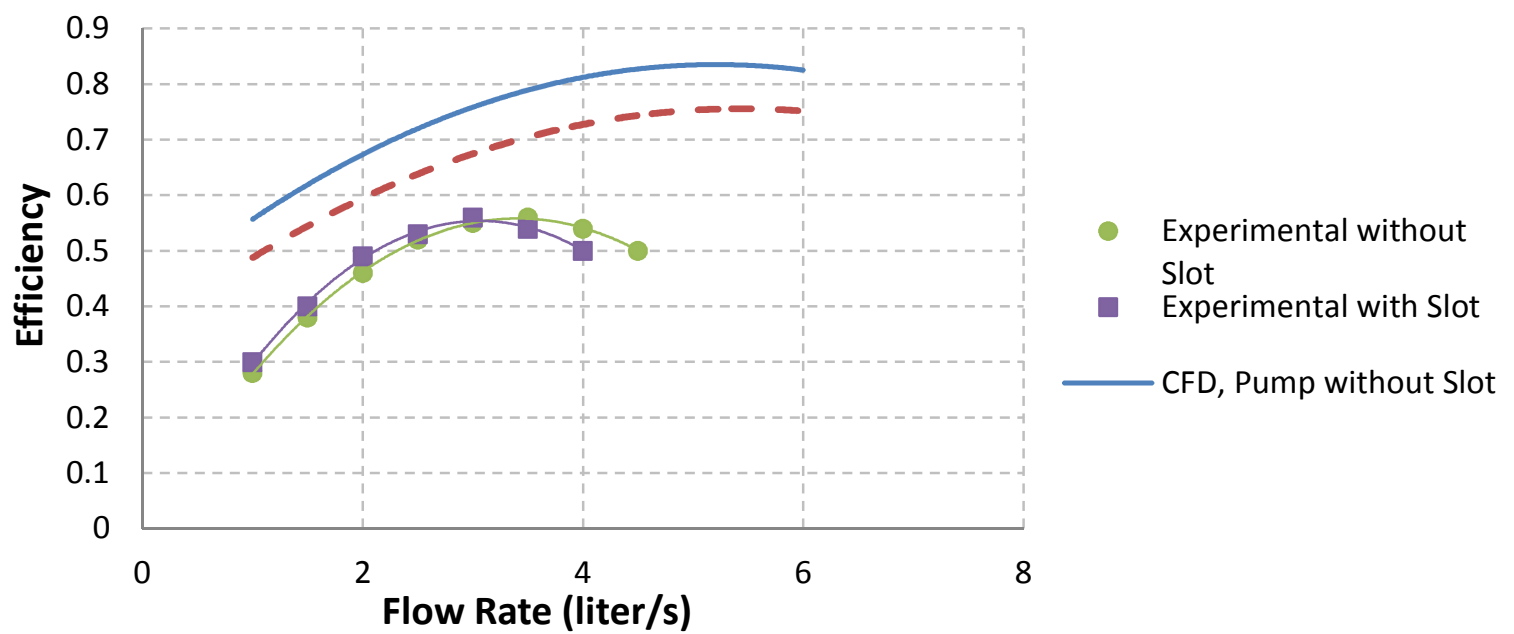

Figure (9). Pump efficiency with and without slot.

The velocity vectors at two different flow rates are investigated; $Q=1$ liter $/$ s, at partload condition and $Q=3.5 \mathrm{~L} / \mathrm{s}$ at the best efficiency point. In Figure (10), the velocity vectors for part load condition indicate two circulations: the first one is created on the pressure side near the impeller outlet with a small size and high velocity. The second one is created on the suction side with large size and small velocity. The flow enters the impeller at an angle of attack causing the suction side circulation. In the presence of the slot, the fluid flowing throughout the slot reduces the size of the suction side circulation. Figure (11) indicates the absence of the two circulations. When increasing velocity the pressure side circulation dies out, and when the angle of attack approaching zero the suction side circulation is disappears.

The static pressure contours are also investigated at the flow rate $Q=3.5$ liter $/ \mathrm{s}$. Figure (12) shows the contours of the static pressure of the impeller with and without blade slot.

In conclusion, the head decreases at large values of the slot height $h_{s}$. Therefore, in the present study, attention will be directed to a smaller slot height $h_{s}$, together with a new parameter, namely the slot inclination angle $\theta_{\mathrm{s}}$. 

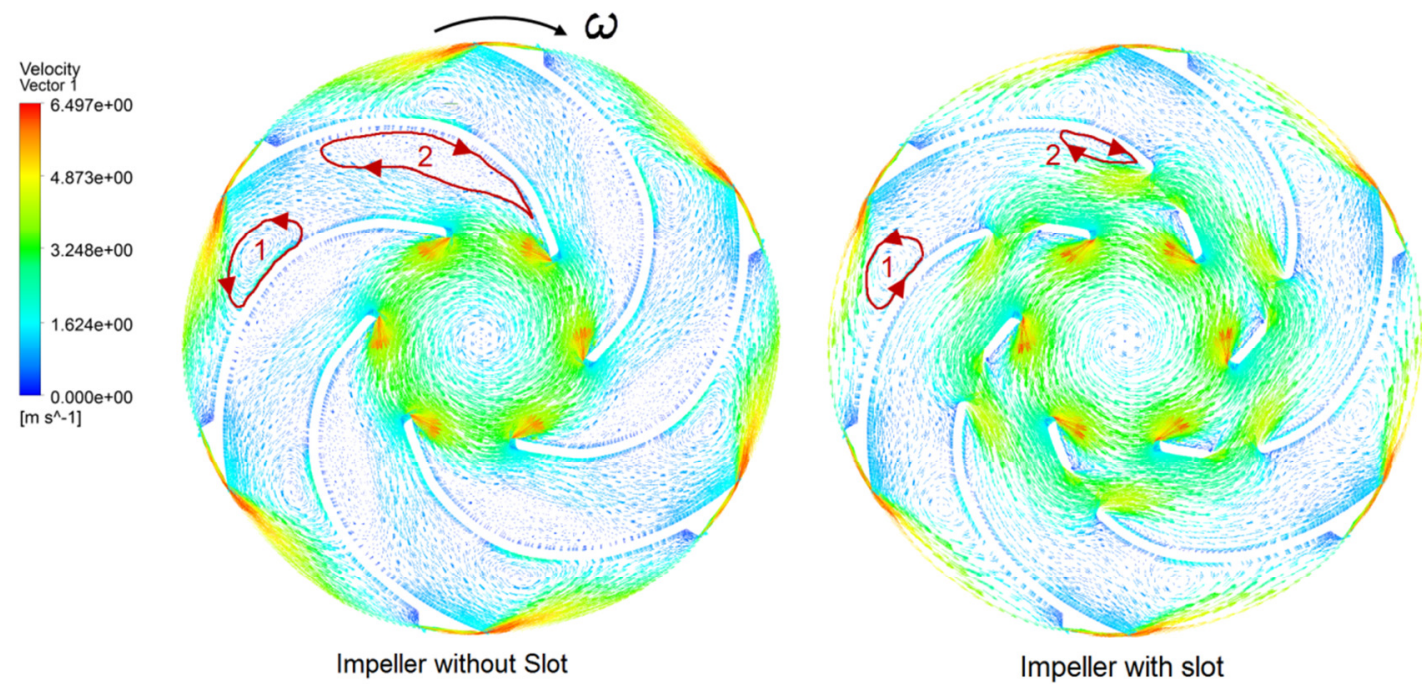

Figure (10). Impeller relative velocity vector at flow rate $Q=1 \mathrm{~L} / \mathrm{s}$ on mid span.

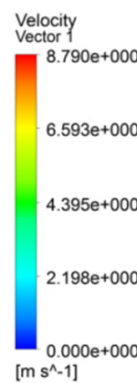

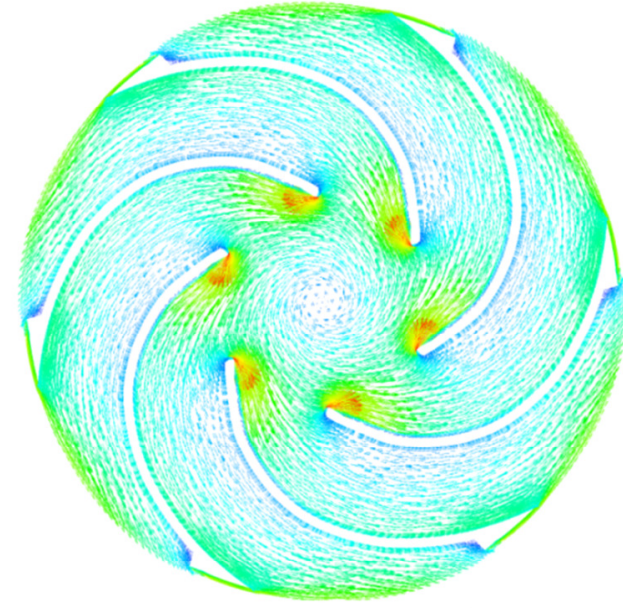

Impeller without Slot
Impeller with Slot

Figure (11). Impeller relative velocity vector at flow rate $Q=3.5 \mathrm{~L} / \mathrm{s}$ on mid span.
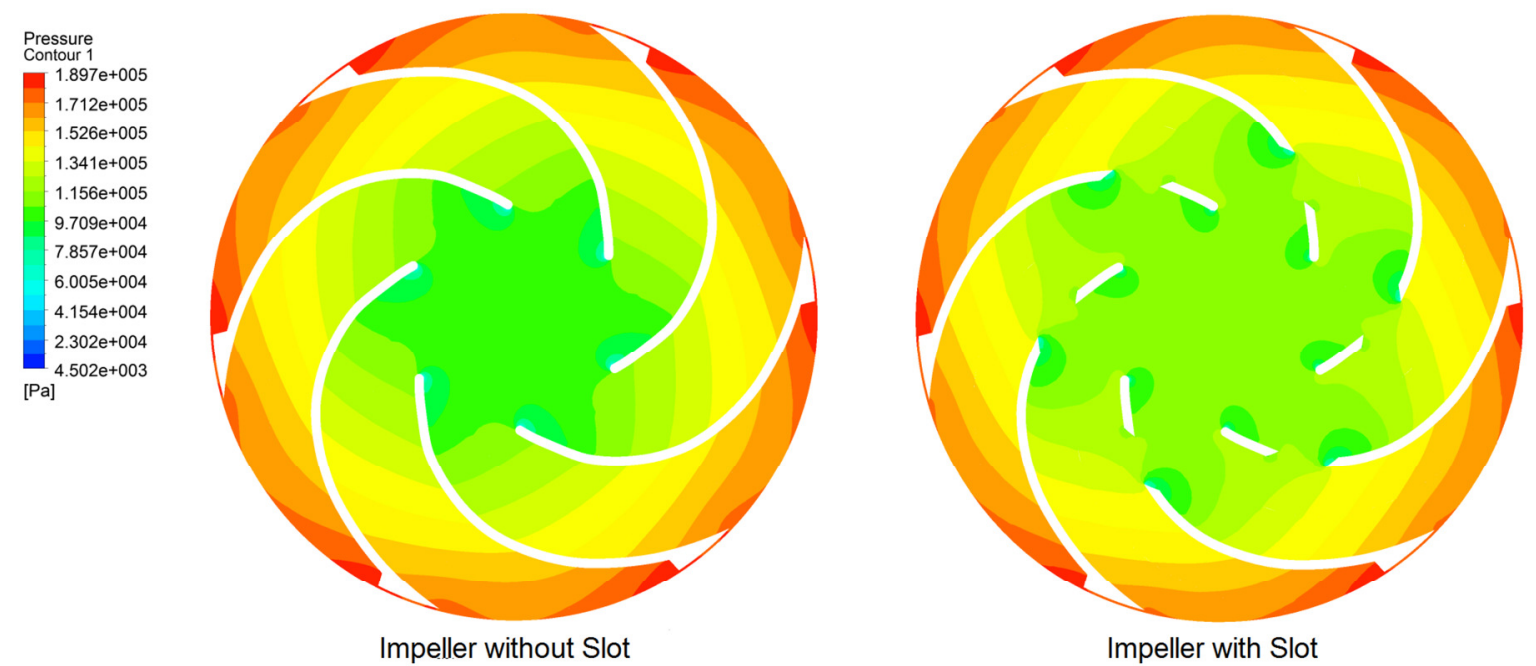

Figure (12). Impeller static pressure contour at flow rate $Q=3.5 \mathrm{~L} / \mathrm{s}$ at mid span. 


\section{RESULTS AND DISCUSSIONS}

A single arc blade design is assumed, and the pump speed is chosen $n=$ $1500 \mathrm{rpm}$ with impeller outer diameter $D_{2}=130 \mathrm{~mm}$ and impeller inner diameter $D_{1}=50 \mathrm{~mm}$. The other dimensions are chosen according to Table 1 . Fifteen cases have been studied to cover the slot parameters that affect the impeller performance, Table (2). When making a slot in the impeller blade the fluid goes through this slot from the pressure side to the suction side with certain flow rate. The convergence of this mass flow rate is shown in Figure (13).

Table (2). Different cases of slot parameters.

\begin{tabular}{|c|c|c|c|c|}
\hline Case & Parameter & $\begin{array}{c}\text { Slot Position } R_{s} \\
(\mathrm{~mm})\end{array}$ & $\begin{array}{c}\text { Slot inclination } \\
\text { angle } \theta_{s} \text { (degree) }\end{array}$ & $\begin{array}{c}\text { Slot Height } \boldsymbol{h}_{s} \\
(\mathrm{~mm})\end{array}$ \\
\hline 1 & \multirow{5}{*}{ 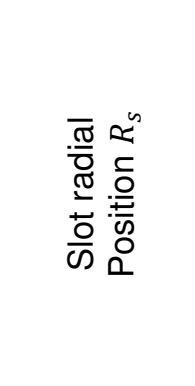 } & 35 & \multirow{5}{*}{ Zero } & \multirow{5}{*}{1} \\
\hline 2 & & 40 & & \\
\hline 3 & & 45 & & \\
\hline 4 & & 50 & & \\
\hline 5 & & 55 & & \\
\hline 6 & \multirow{5}{*}{ 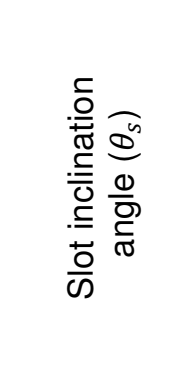 } & \multirow{5}{*}{45} & 20 & \multirow{5}{*}{1} \\
\hline 7 & & & -45 & \\
\hline 8 & & & -90 & \\
\hline 9 & & & -110 & \\
\hline 10 & & & -130 & \\
\hline 11 & \multirow{5}{*}{ 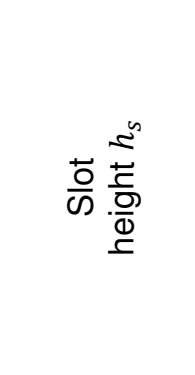 } & \multirow{5}{*}{45} & \multirow{5}{*}{-90} & 0.5 \\
\hline 12 & & & & 1 \\
\hline 13 & & & & 1.5 \\
\hline 14 & & & & 2 \\
\hline 15 & & & & 2.5 \\
\hline
\end{tabular}

\section{Effect of Slot Radial Position}

The effect of the variation of the slot radial position $R_{s}$ on the impeller performance is studied by changing its value and keeping the values of the other parameters constant; Cases (1-5) in Table (2). Figure (14) shows the head versus the slot radial position. It is found that the head decreases with increasing $R_{s}$ in other word; a slot located closer to the blade root is preferred for all value of flow rate inspected. No improvement in the impeller performance has been detected. In addition, Figure (15) shows that $R_{s}$ has a small impact on the impeller hydraulic efficiency. 


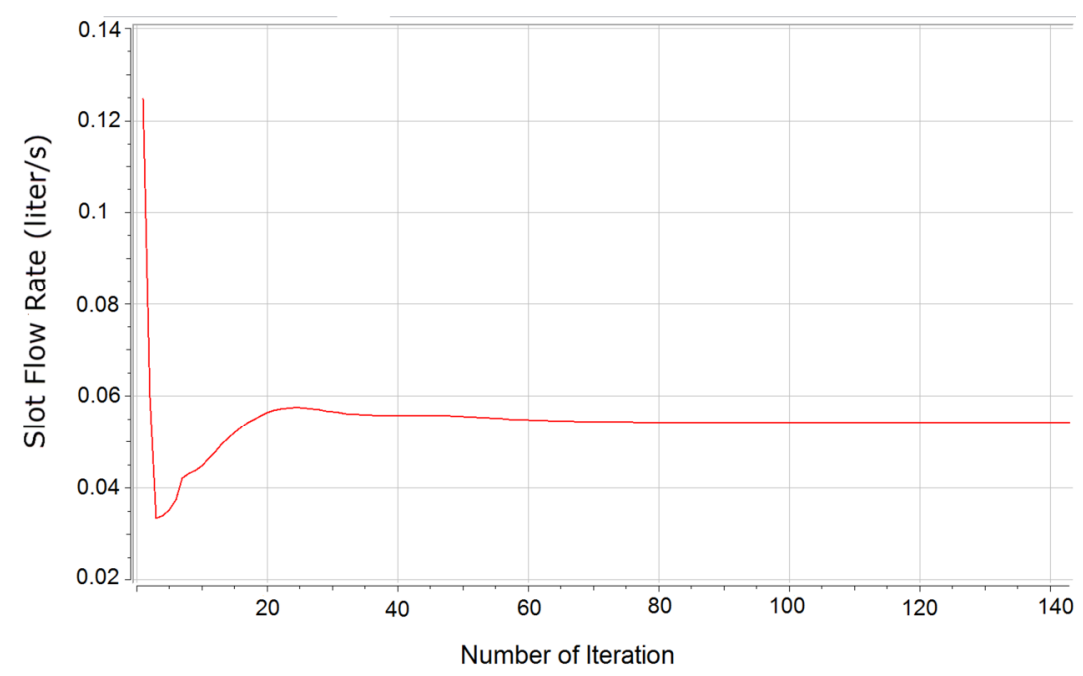

Figure (13). Convergence history of flow rate through the slot (Case 3 ) at pump flow rate $Q=4$ liter $/ \mathrm{s}$.
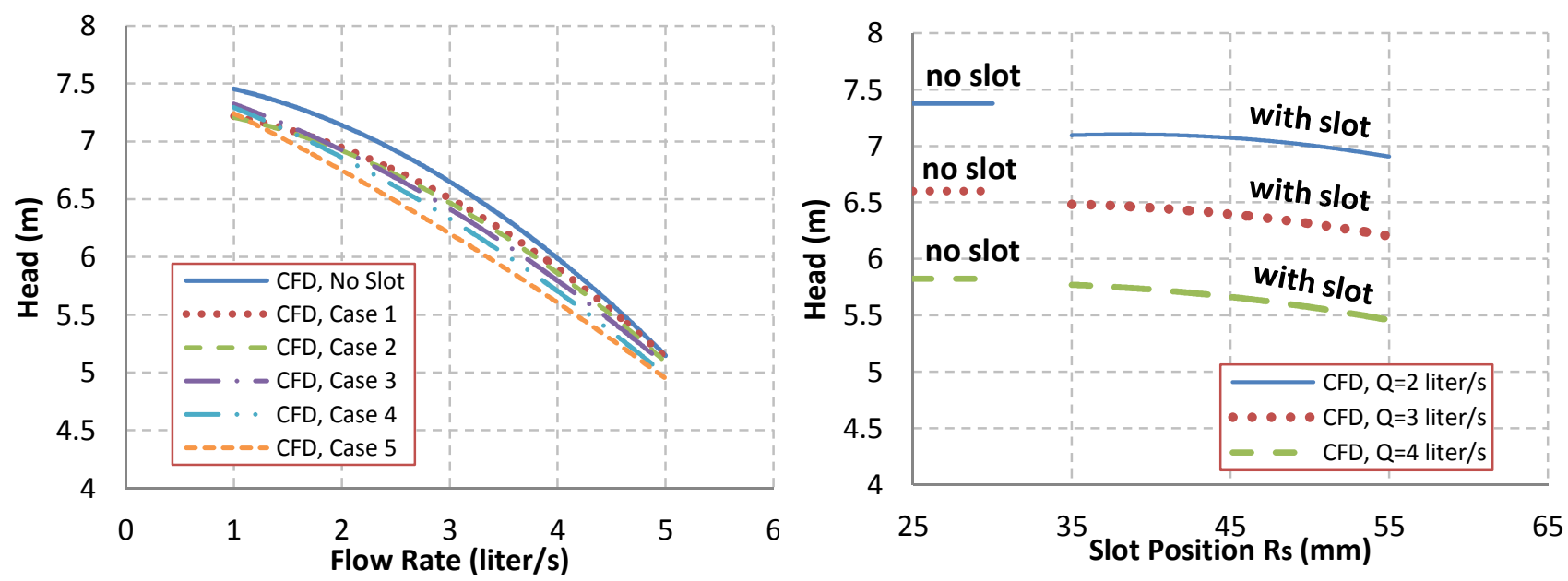

Figure (14). Effect of slot radial position $\mathrm{R}_{\mathrm{s}}$ on the impeller head, $h_{s}=1 \mathrm{~mm} \& \theta_{s}=0^{\circ}$.
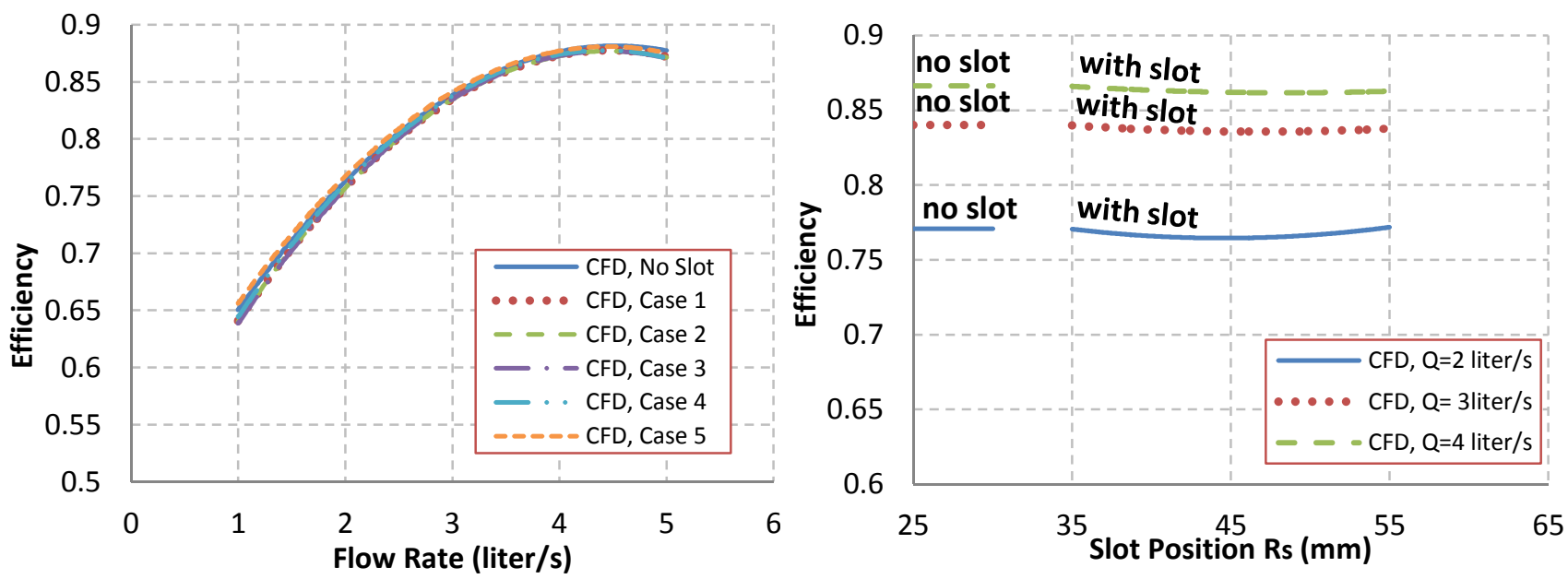

Figure (15) Effect of slot radial position Rs on the impeller hydraulic Efficiency $h_{s}=1 \mathrm{~mm} \& \theta_{s}=0^{\circ}$. 


\section{Effect of Slot Inclination Angle}

The effect of the slot inclination angle on the impeller head is addressed in the cases (6-10). From the blade geometry there is a constrain on the slot inclination angle and it should be chosen according to Eq.(7)

$$
-180+\beta<\theta_{s}<\beta
$$

where $\beta$ = blade angle at slot radial position $R_{S}$,

Results show that the high negative inclination angle causes higher heads as shown in Figure (16). This increase in head was due to the rise in slip factor. The effect of the slot inclination angle on the hydraulic efficiency of the impeller is shown in Figure (17). Sharp reduction in efficiency is noted at slot inclination $\theta_{s}<-110^{\circ}$ this drop in efficiency is attributed to the high change in the relative velocity direction. A similar drop in efficiency can be noted in at slot inclination angle $\theta_{s}>0^{\circ}$.
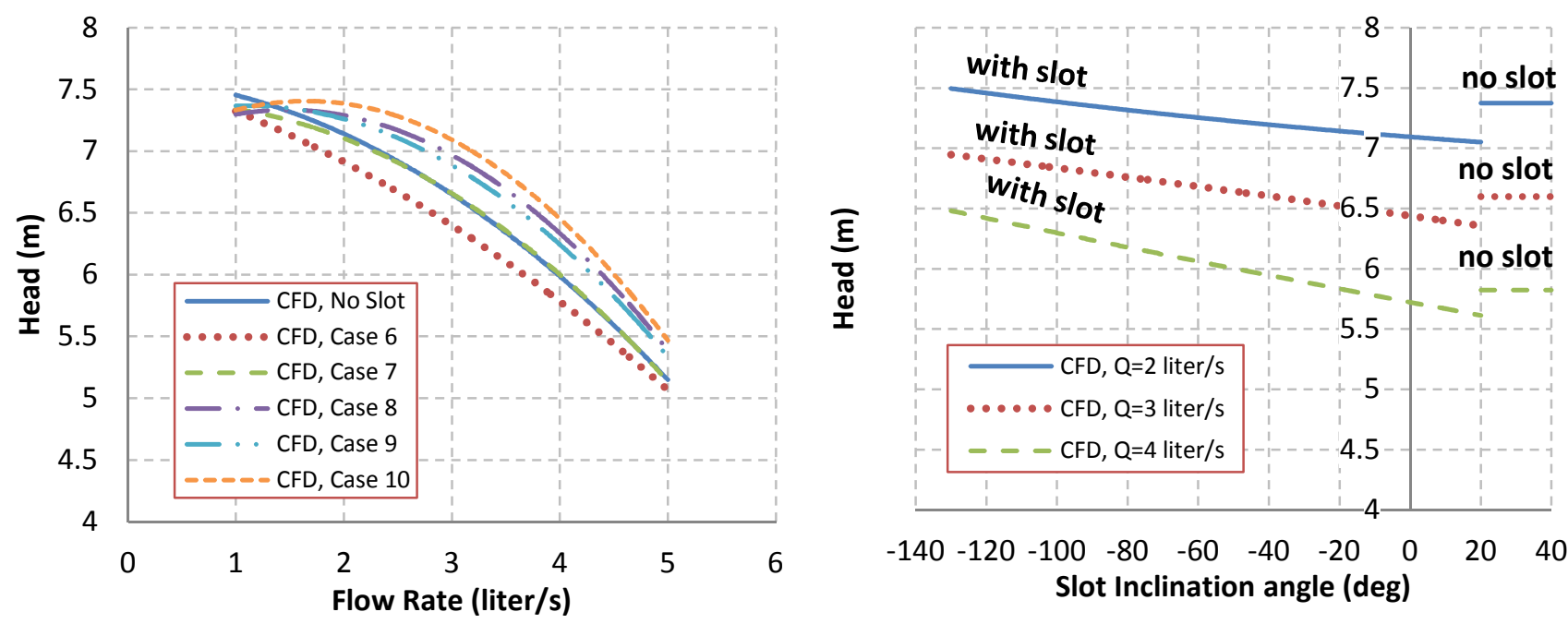

Figure (16) Effect of slot inclination angle $\boldsymbol{\theta}_{\boldsymbol{s}}$ on the impeller head, $R_{s}=45 \mathrm{~mm} \& h_{s}=1 \mathrm{~mm}$.
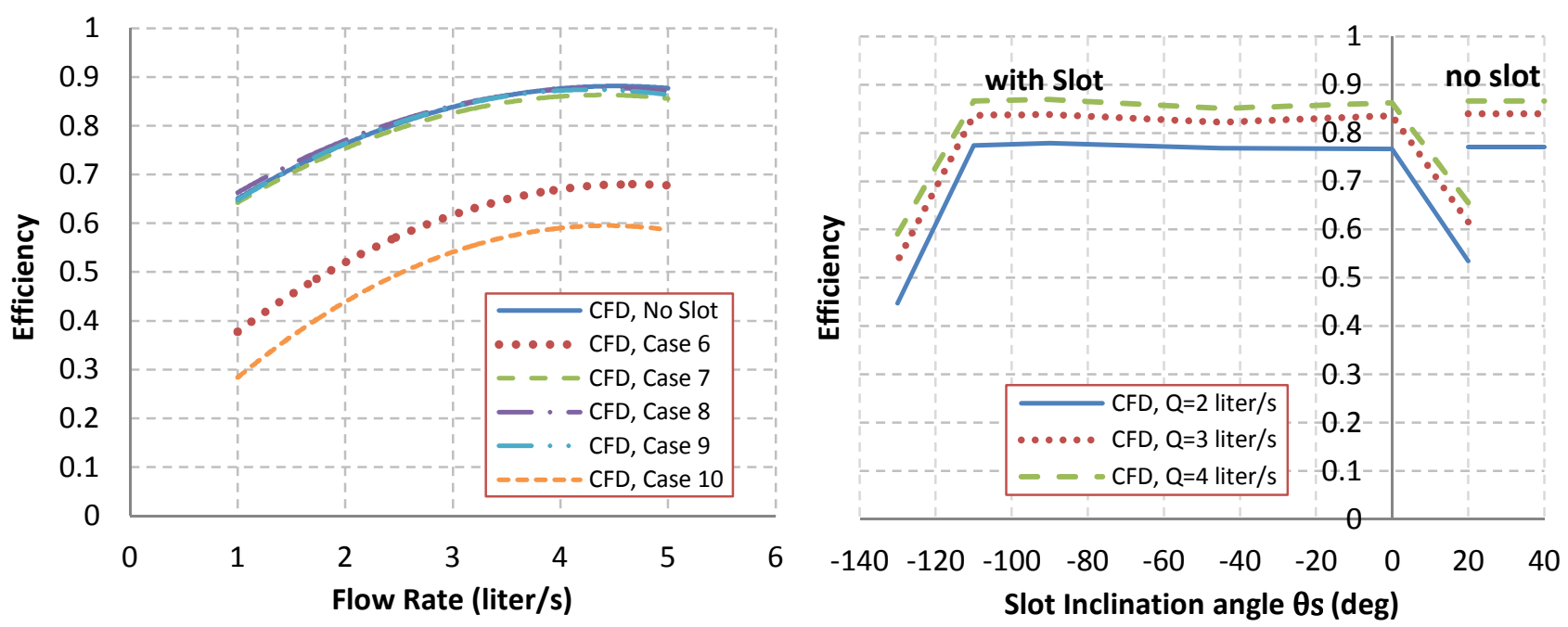

Figure (17). Effect of slot inclination angle $\boldsymbol{\theta}_{s}$ on the impeller hydraulic efficiency, $R_{s}=45 \mathrm{~mm} \& h_{s}=1 \mathrm{~mm}$. 


\section{Effect of the Slot Height}

Finally, the effect of the slot height on the impeller head is examined, cases (11-15). Figure (18) shows that with increasing slot height the head increases up to certain value then it decreases. Figure (19) shows the impeller hydraulic efficiency. It decreases with the increase of slot height.
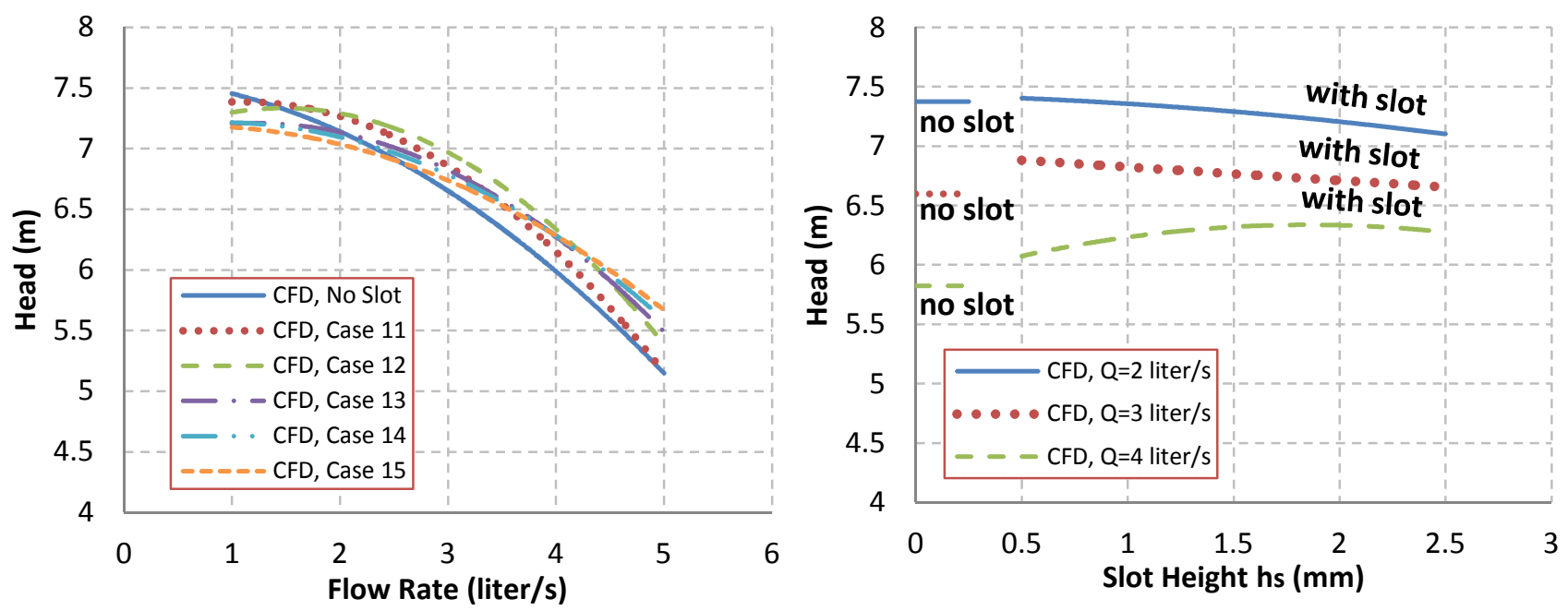

Figure (18). Effect of slot height $h_{s}$ on the impeller head, $R_{S}=45 \mathrm{~mm} \& \theta_{s}=-90^{\circ}$.
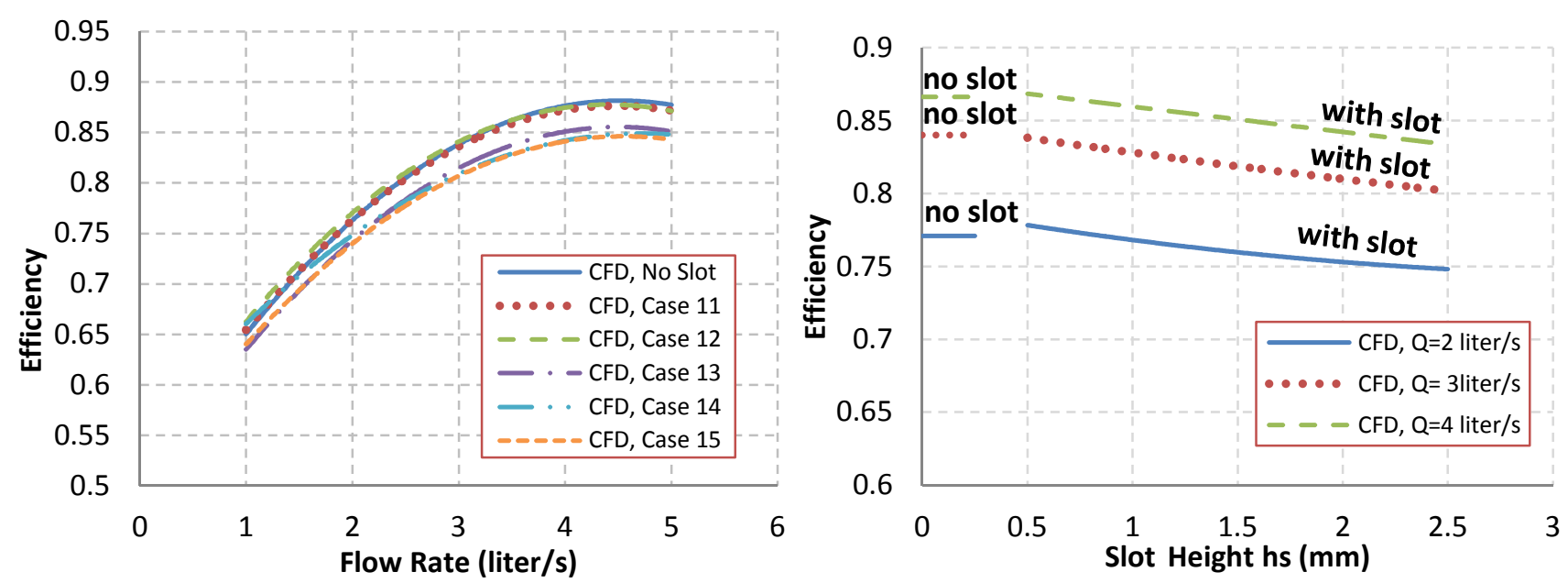

Figure (19). Effect of slot height $h_{s}$ on the impeller hydraulic efficiency, $R_{s}=$ $45 \mathrm{~mm} \& \theta_{s}=-90^{\circ}$.

\section{Impact of Slot on Flow Field Features}

Figure (20) shows the relative velocity vectors on the mid span at flow rate $Q=4 \mathrm{~L} / \mathrm{s}$ (case 11) for impeller with and without slots. Formation of a vortex on the suction side with the same angular direction of the impeller rotation increases the slip factor and hence increases the head.

Figure (21) shows the difference in pressure along the blade pressure and suction sides. Clearly, the pressure difference above the slot is higher than the pressure difference in case of blade without slot. 
To illustrate the effect of the blade slot on the performance of the impeller, the pressure contours and the velocity vector inside the slot are shown in Figure (22) and Figure (23). The pressure contours inside the slot show that the pressure force in the slot with inclination angle (case 3 ) has positive direction with y-axis. In addition, for (case 9) the pressure force has a negative direction with the $y$-axis.

The velocity vector in the blade slot shows that the velocity has a large value at the slot upper half. In case of high inclination angle, the velocity has a reverse flow in the lower slot region. The velocity in the slot has maximum value (about $5.8 \mathrm{~m} / \mathrm{s}$ ). The flow rate inside the slot is proportional to the slot height, in case of $h_{s}=1 \mathrm{~mm}$ the slot flow rate is about 0.055 liter $/ \mathrm{s}$ with the total flow rate equal to 4 liter $/ \mathrm{s}$ as shown in Figure (13), which represents $\approx 1.4 \%$.

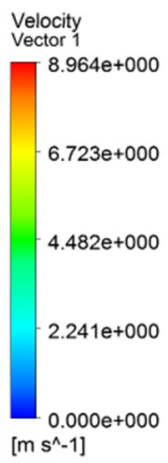

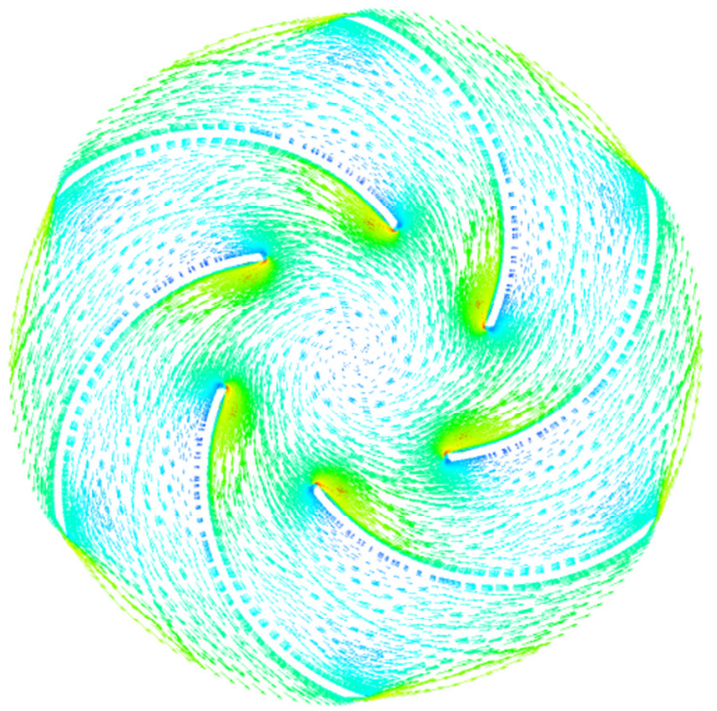

Impeller Without Slot

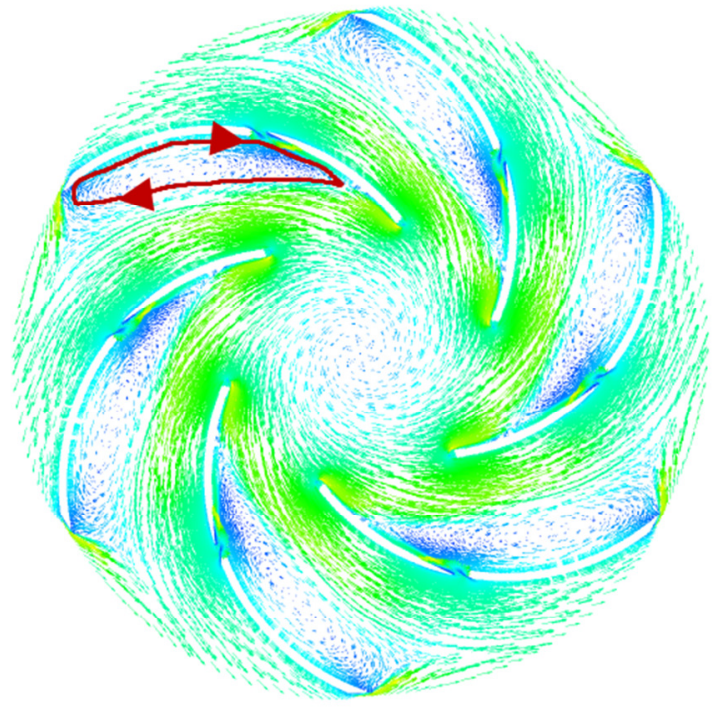

Impeller With Slot (Case 11)

Figure (20). Relative velocity vectors on mid span at flow rate $Q=4 \mathrm{~L} / \mathrm{s}$.

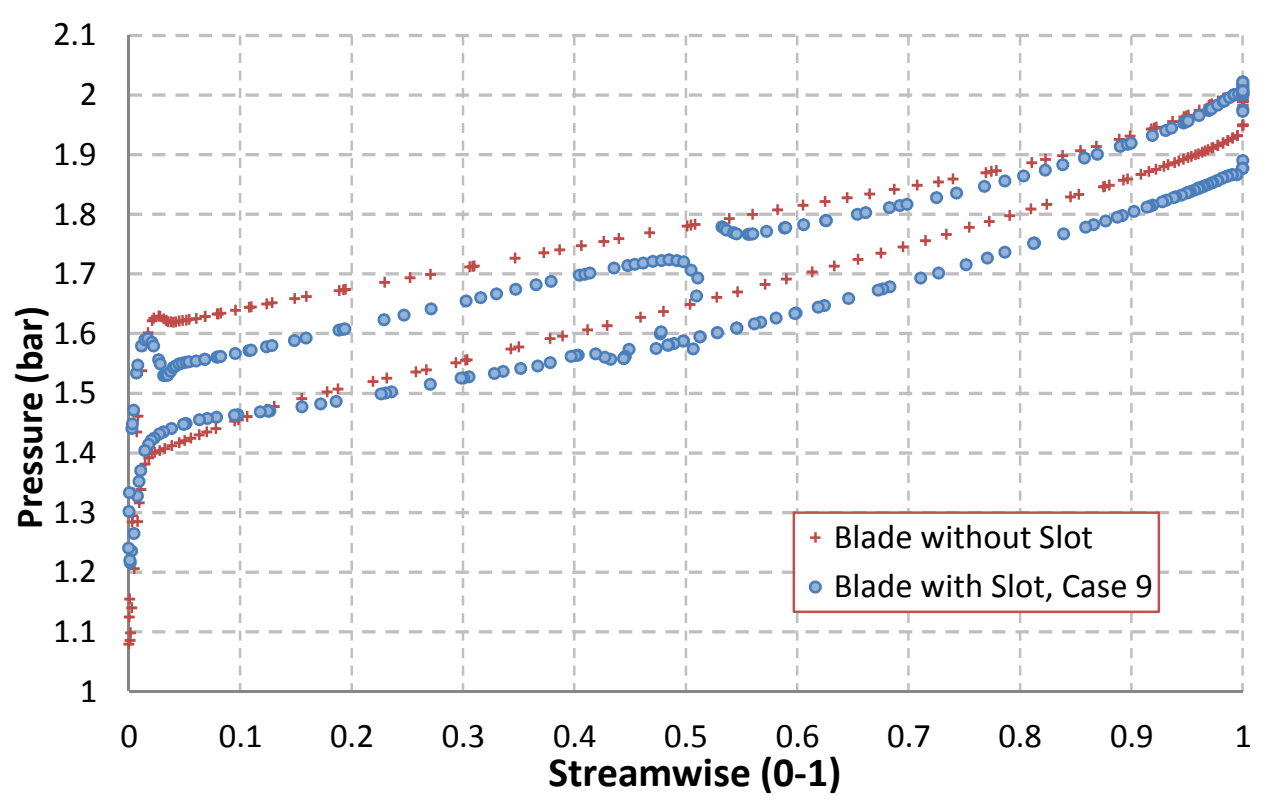

Figure (21). Streamwise Blade loading on mid-span at flow rate $Q=4 \mathrm{~L} / \mathrm{s}$. 

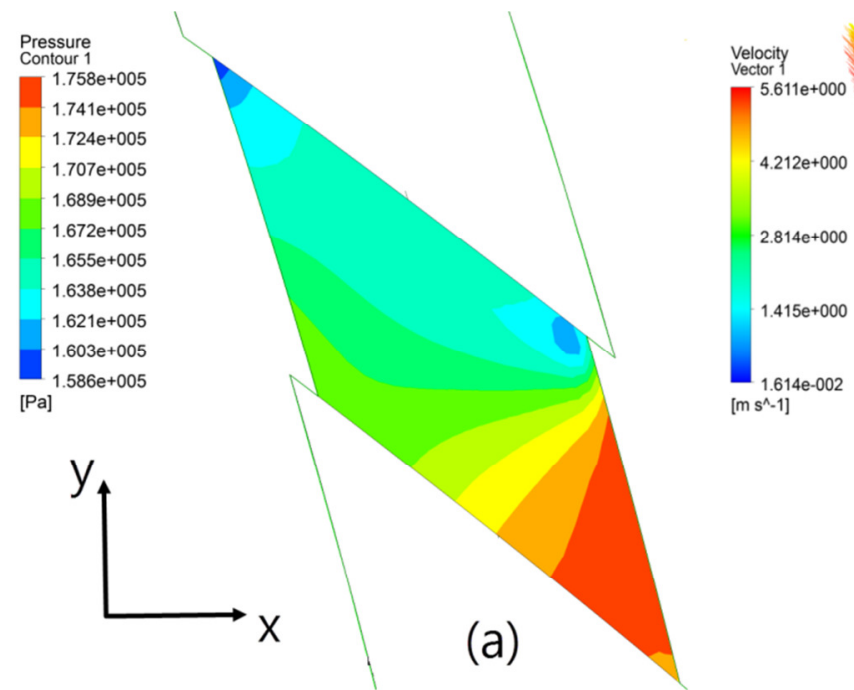

(a)

(b)

Figure (22). (a) pressure contours, and (b) relative velocity vector a cross the slot (case 3) at flow rate $Q=4 \mathrm{~L} / \mathrm{s}$.
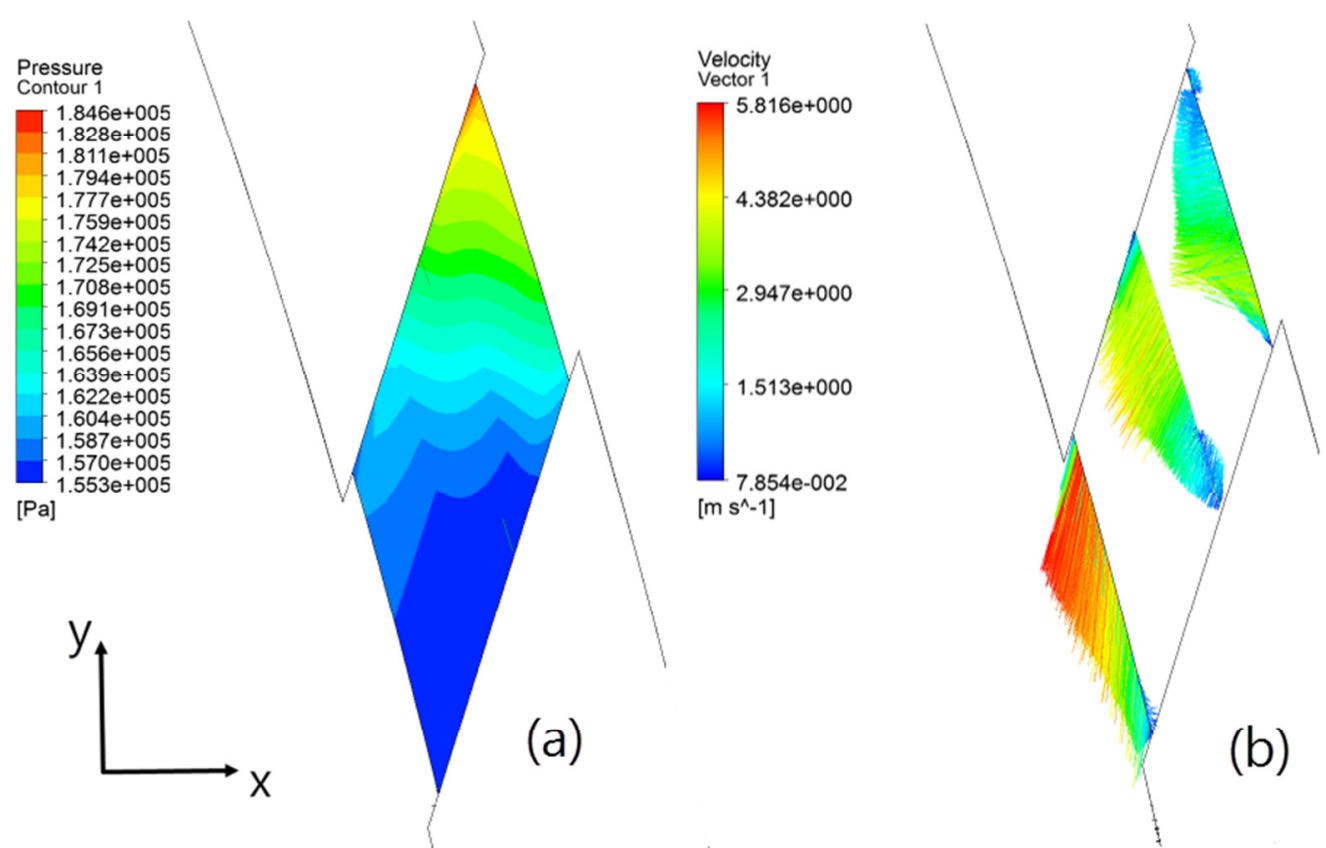

Figure (23). (a) pressure contours, and (b) relative velocity vector a cross the slot (case 9) at flow rate $Q=4 \mathrm{~L} / \mathrm{s}$.

\section{CONCLUSIONS}

In the present work, a parametric study is done based on the blade slot technique to investigate the effect of some slot geometrical parameters, namely slot radial position $\left(R_{S}\right)$, slot height $\left(h_{s}\right)$ and slot inclination angle $\left(\theta_{s}\right)$ on the impeller performance using a 3-D numerical simulation of a turbulent flow inside the centrifugal impeller, the following are concluded:

- With increasing the slot radial position $R_{S}$ the impeller head is decreased. The slot radial position has an effect less than $2.5 \%$ on the impeller hydraulic efficiency when the slot height is $1.5 \%$ of the blade length. 
- The slot inclination angle has a significant effect on the impeller head and efficicency. The slot with inclination angle $-130^{\circ}<\theta_{s}<-90^{\circ}$ has a high impeller head with 5-10\% above the impeller head without slot. The optimum efficiency can be reached within the range of slot inclination angle $-110^{\circ}<\theta_{s}<0^{\circ}$.

- At the part load operating zone, the impeller head decreases with increasing the slot height, then at the over load zone the impeller head increase with increasing the slot height upto certain slot height value then the impeller head deacrease. The efficiency is decreased with the increase of slot height.

Attempts have been made to explain the physics of impeller with slot design. The present work is currently extended by incorporating the complete pump geometry to account for the discrepancies between CFD and experimental finding.

The study can be further extended to optimize the slot design parameters at different flow rates for maximum pump performance.

\section{REFERENCES}

[1] J. F. Gülich, Centrifugal pumps: Springer, 2010.

[2] L. Wen-Guang, "Experiments on impeller trimming of a commercial centrifugal oil pump," presented at the International Conference on Hydraulic Machinery and Hydrodynamics, 2004.

[3] W. G. Li, "Impeller trimming of an Industrial Centrifugal Viscous Oil Pump," International Journal of Advanced Design and Manufacturing Technology, vol. 5, pp. 1-10, 2012.

[4] M. Savar, H. Kozmar, and I. Sutlović, "Improving centrifugal pump efficiency by impeller trimming," Desalination, vol. 249, pp. 654-659, 2009.

[5] G. Kergourlay, M. Younsi, F. Bakir, and R. Rey, "Influence of splitter blades on the flow field of a centrifugal pump: test-analysis comparison," International Journal of Rotating Machinery, vol. 2007, 2007.

[6] B.-I. Cui, Y.-g. Lin, and Y.-z. Jin, "Numerical simulation of flow in centrifugal pump with complex impeller," Journal of Thermal Science, vol. 20, pp. 47-52, 2011.

[7] S. Yuan, J. Zhang, Y. Tang, J. Yuan, and Y. Fu, "Research on the Design Method of the Centrifugal Pump with Splitter Blades," in Proceedings of the ASME 2009 Fluids Engineering Division Summer Meeting, 2009.

[8] L. Wen-Guang, "Blade Exit Angle Effects on Performance of a Standard Industrial Centrifugal Oil Pump," Journal of Applied Fluid Mechanics, vol. 4, pp. 105-119, 2011.

[9] W. Li, "Effect of exit blade angle, viscosity and roughness in centrifugal pumps investigated by CFD computation," Task quarterly, vol. 15, pp. 21-41, 2011.

[10] M. Patel and A. Doshi, "Effect of Impeller Blade Exit Angle on the Performance of Centrifugal Pump," Intrnational Journal of Emerging Technology and Advanced Engineering, vol. 3, pp. 702-709, 2013.

[11] E. Bacharoudis, A. Filios, M. Mentzos, and D. Margaris, "Parametric study of a centrifugal pump impeller by varying the outlet blade angle," Open Mechanical Engineering Journal, vol. 2, pp. 75-83, 2008. 
[12] M. H. S. Fard and F. Boyaghchi, "Studies on the Influence of Various Blade Outlet Angles in a Centrifugal Pump when Handling Viscous Fluids," American Journal of Applied Sciences, vol. 4, pp. 718-724, 2007.

[13] S. Chakraborty, K. Pandey, and B. Roy, "Numerical Analysis on Effects of Blade Number Variations on Performance of Centrifugal Pumps with Various Rotational Speeds," International Journal of Current Engineering and Technology, vol. 2, pp. 143-152, 2012.

[14] H. Liu, Y. Wang, S. Yuan, M. Tan, and K. Wang, "Effects of blade number on characteristics of centrifugal pumps," Chinese Journal of Mechanical Engineering, vol. 23, pp. 742-747, 2010.

[15] K. Rababa, "The effect of blades number and shape on the operating characteristics of groundwater centrifugal pumps," European Journal of Scientific Research, vol. 52, pp. 243-251, 2011.

[16] M.-g. Tan, H.-I. Liu, S.-q. Yuan, Y. Wang, and K. Wang, "Effects of blade outlet width on flow field and characteristic of centrifugal pumps," in Proceedings of the ASME 2009 Fluids Engineering Division Summer Meeting, Colorado, USA, 2009.

[17] L. Zhou, W. Shi, and S. Wu, "Performance optimization in a centrifugal pump impeller by orthogonal experiment and numerical simulation," Advances in Mechanical Engineering, vol. 2013, 2013.

[18] E. A. Ahmmed, "Study of Flow Field in a Radial vaned Impeller of a Centrifugal Pump \& its Effect on Pump Performance," M.Sc., Mechanical Power \& Energy, MTC, Egypt, 1995.

[19] E. A. Ahmed, A. H. Lotfy, and I. Saleh, "Vortex Control in a Centrifugal Pump Impeller with Radial Slotted Vanes," International AMME Conferance vol. 8, pp. 425-441, 1998.

[20] M. S. El-Din, "Control of flow field inside a centrifugal pump impeller for better performance," MSc, Mechanical Power \& Energy, MTC, Egypt, 2001.

[21] M. S. Hussien, A. H. Lotfy, H. M. Abdalla, and I. Saleh, "Optimum Slot Size and Location in a Radial Vane Impeller for Better Centrifugal Pump Performance," presented at the 9 th International Conference on Aerospace Sceinces \& Aviation Technology, MTC, Cairo, Egypt, 2001.

[22] M. S. Hussien, A. H. Lotfy, H. M. Abdalla, and I. Saleh, "Determination of Optimum Slot in Backward Vane Impeller for Better Centrifugal Pump Performance," presented at the 11-th International Conference on Aerospace Science \& Aviation Technology, MTC, Cairo, Egypt, 2005.

[23] C. Hongxun, L. Weiwei, J. Wen, and W. Peiru, "Impellers of low specific speed centrifugal pump based on the draughting technology," in IOP Conference Series: Earth and Environmental Science, 12, 2010.

[24] W. Wahba, "Flow Pattern in a Centrifugal Pump Used in Turbo-Pump Feeding System," MSc, MTC, Egypt, 1997.

[25] L. Wen-Guang, "Numerical study on behavior of a centrifugal pump when delivering viscous oils-part 1: performance," International Journal of Turbo and Jet Engines, vol. 25, pp. 61-79, 2008.

[26] "ANSYS® 14.5.7 CFX-Solver Theory Guide," 2012.

[27] M. Shojaeefard, M. Tahani, M. Ehghaghi, M. Fallahian, and M. Beglari, "Numerical study of the effects of some geometric characteristics of a centrifugal pump impeller that pumps a viscous fluid," Computers \& Fluids, vol. 60, pp. 61-70, 2012.

[28] "ANSYS® 14.5.7 CFD-Post User's Guide," 2012. 